\title{
Optimization of laccase production and its application in delignification of biomass
}

\author{
Zabin K. Bagewadi ${ }^{1,2}$ (D) Sikandar I. Mulla ${ }^{1} \cdot$ Harichandra Z. Ninnekar $^{1}$
}

Received: 1 April 2017/Accepted: 28 October 2017/Published online: 7 November 2017

(C) The Author(s) 2017. This article is an open access publication

\begin{abstract}
Purpose Current research focuses on the biological delignification of biomass by microbial laccase which is an environmentally friendly process.

Methods Various statistical approaches were designed for optimization of laccase production like Plackett-Burman design as well as response surface methodology (RSM). A laccase mediator system was designed for the delignification of saw dust which was molecularly characterized by high-performance liquid chromatography (HPLC), Fourier transformation infrared spectroscopy (FTIR) and scanning electron microscopy (SEM).

Results The present study reveals wheat bran is a potential substrate for the production of laccase $(63 \mathrm{U} / \mathrm{g}$ and $9.6 \mathrm{mg} /$ $\mathrm{g}$ protein) under solid-state fermentation by Trichoderma harzianum strain HZN10. Statistical optimization by RSM using central composite design (CCD) revealed that wheat bran contributed maximally to the overall laccase production followed by yeast extract. Laccase production under optimized conditions yielded $510 \mathrm{U} / \mathrm{g}$ with 8.09 -fold increase. HPLC peaks representing 4-hydroxy-3-methoxybenzoic (vanillic) acid and 4-hydroxy-3,5-dimethoxybenzoic (syringic) acid showed drastic reduction in laccasetreated saw dust sample indicating the elimination of toxic inhibitors, thereby signifying the detoxification of sample.
\end{abstract}

Zabin K. Bagewadi

zabinb@gmail.com

$凶$ Harichandra Z. Ninnekar

hzninnekar@yahoo.com

1 Department of Biochemistry, Karnatak University, Dharwad, Karnataka 580 003, India

2 Department of Biotechnology, KLE Technological University, Hubballi, Karnataka 580 031, India
The laccase-treated saw dust showed 1.6-fold increase in reducing sugars after enzymatic (cellulase) hydrolysis. The FTIR analysis revealed the structural alterations occurring during the delignification process. SEM of biologically treated saw dust revealed the morphological alterations during the delignification process targeting the fiber cell walls rich in lignin.

Conclusion The delignification of saw dust was effective by laccase mediator system and was evidenced by HPLC, FTIR and SEM analysis. Hence, laccase can be a powerful tool in biomass to biofuel conversions.

Keywords Laccase - Trichoderma sp. P Plackett-Burman . Response surface methodology $\cdot$ Delignification

\section{Introduction}

The rising concerns on the scarcity and exhaustion of fossils fuels and their related environmental impacts have forced the research toward the development of sustainable alternatives such as conversion of lignocellulosic biomass to biofuels (Sun and Cheng 2002). Currently, production of biofuels such as cellulosic bioethanol is a challenging task due to the bottle necks related to the saccharification process (Taha et al. 2015). The complex recalcitrant structure of lignocellulose comprises of cellulose, hemicelluloses and lignin. Lignin is a highly complex irregular branched three-dimensional polyphenolic polymer consisting of different functional entities like phenyl propanoid units of coniferyl, sinapyl and $p$-coumaryl alcohols. Functional groups such as phenolic hydroxyl, benzylic hydroxyl and carbonyl moieties were linked to lignin backbone and phenyl propanoid, thereby making them more complex (Vivekanand et al. 2008). Lignin 
contributes to the structural integrity and stability of plant cell walls and resists the enzymatic hydrolysis of hemicellulose. Hence, a pretreatment process is essential to alter or eliminate the lignin so as to progress the rate of enzymatic hydrolysis of cellulose or hemicellulose to fermentable sugars (Wyman et al. 2005). Various pretreatment processes are used in industries such as steam explosion and chemical pretreatments employing alkali and acids which significantly alters the structure of lignin (Alvira et al. 2010). During the pretreatment process, several inhibitory compounds like phenolics (syringaldehyde, $p$-hydroxybenzaldehyde and vanillin) are formed during lignin degradation which inhibits the enzymes involved in hydrolysis and also interferes in the fermentation process (Parawira and Tekere 2011). These chemicals are also known to damage the strength of the living cell membranes, thereby influencing their property to act as discriminating barriers. They also affect by inhibiting the cell growth and sugar metabolism. However, the nature of such toxic chemicals also depends on composition of the biomass and harsh pretreatment processes (Kalyani et al. 2012). Physical methods like evaporation and chemical methods like solvent extraction, ion exchange and activated charcoal adsorption are available for the removal of the inhibitory toxic compounds but increase the overall production cost (Carter et al. 2011). A biological alternative for the detoxification process would be the employment of microbial systems and their enzymes such as laccases. The delignifications of biomass by microbial systems harboring laccase are gaining popularity due to its environmentally friendly nature (Pandiyan et al. 2014). Laccases (oxygen oxidoreductase, EC 1.10.3.2) are multicopper oxidase that bring about the oxidative process of a group of chemical with the aid of four copper atoms present in the catalytic core and subsequently reduce oxygen to water molecules (Frasconi et al. 2010). The action of laccase on lignin is limited to the phenolic units and hence could be extended by the use of synthetic electron carriers like 1-hydroxybenzotriazole (HBT). These electron carriers act as redox mediators between the enzyme and substrate. The usage of these mediators explores wide biotechnological applications of laccase (Rico et al. 2014). Laccases play a significant role in morphogenesis and pathogenesis. Laccases have been identified to have wide industrial applications such as in lignin degradation, pulp bleaching, decolourization of different azo recalcitrant textile dyes, wastewater treatment, fossil fuel desulfurization, biosolubilization of coal, degradation of herbicides, bioremediation, detoxification of pollutants, synthesis of natural products like pigments and antioxidants, biosensors and immunochemical applications (Arora and Sharma 2010; Kalyani et al. 2012; Lee et al. 2012; Rico et al. 2014). Laccase enzymes are extensively dispersed in environment among the plants, insects, fungus and bacteria (Giardina et al. 2010). White rot fungi is commonly recommended for effective degradation of lignin and laccase production. Various microbial systems such as Schizophyllum commune, Marasmiellus palmivorus, Peniophora sp. have been employed for delignification of different biomasses (Shankar and Shikha 2012; Pandiyan et al. 2014; Kumar et al. 2015). For huge volume of synthesis of enzymes, the agricultural waste residues utilization by solid-state fermentation (SSF) has been an attractive and cost-effective approach. Some of the agricultural waste residues commonly used includes banana peel, apple pomace, brewery waste, wheat straw, wheat bran, rice straw, rice bran, sugarcane bagasse, etc. (Gassara et al. 2011; Vivekanand et al. 2011; Karp et al. 2015; Patel and Gupte 2016). SSF can be applied for the synthesis of several valuable chemical intermediates with many advantages which includes enhanced fungal growth on the contact substrate in moist environment, higher biomass yields, higher product concentration, low energy requirements, less capital investment, less waste generation, simple equipment design and high product recovery (Bagewadi et al. 2016a; Viniegra-González et al. 2003). To enhance enzyme production, several statistical optimization designs are commonly employed. Among them response surface methodology (RSM) has been a versatile and popular technique. RSM is a compilation of statistical and mathematical methods developed for improving the optimization processes. RSM has been employed to study the effect of the variables and their interactions that influence the overall production processes such as microbial enzyme production (Myers and Montgomery 2002). The statistical optimization approach usually involves various steps like designing the experiments with defined levels and factors, executing the statistically intended experimental trials, assessing the factors of the ideal terms, expecting the responses, analysis of variance (ANOVA), checking model adequacy and validation of the obtained model (Diwaniyan et al. 2012). RSM has been successfully used in many biochemical and biotechnological processes for optimization and modeling studies (Bas and Boyaci 2007). Few reports are available on the laccase optimization in Trichoderma harzianum strain by RSM (Gao et al. 2013). However, it is necessary to explore and design strategies for enhanced laccase production by optimization of media and process parameters using statistical approaches.

The present study was aimed to statistically optimize laccase production and its utilization for biomass delignification process. Hence, the present research outlines the production of laccase from a previously isolated fungal strain (Trichoderma harzianum strain HZN10) 
using various agricultural waste residues under SSF and statistical optimization of fermentation process parameters using CCD-RSM design to enhance the laccase yield. The effect of laccase mediator system in delignification and detoxification of biomass (saw dust) was assessed by Fourier transform infrared spectroscopy (FTIR), high-performance liquid chromatography (HPLC) and scanning electron microscopy (SEM), which provides the molecular insights of the structural changes occurring in the lignin. The saccharification of laccase-pretreated biomass (saw dust) was also evaluated that gives industrial relevance.

\section{Materials and methods}

\section{Substrates and materials}

Substances and constituents of medium were of analytical grade and procured from Sigma-Aldrich Pvt Ltd. (USA), HiMedia (India) and Merck (USA). The different agricultural residues used in the present study were wheat bran (WB), rice straw (RS), sugarcane bagasse (SB), corn cobs (CC), saw dust (SD) and groundnut shells (GS) which were obtained from local market, wood cutting mills and various agricultural fields. Leaf litter (LL) waste was collected from local vegetable markets.

\section{Production of fungal laccase under SSF}

A laccase-producing fungal strain was used in the present study, which was previously isolated from vermicompost samples. The fungi was identified as Trichoderma harzianum strain HZN10 on the basis of 18S rDNA gene sequencing and deposited to National Center for Biotechnology Information (NCBI) with GenBank accession number KP050785. SSF process for laccase production by Trichoderma harzianum strain HZN10 was performed in 250-ml glass (Erlenmeyer) flasks consisting $10 \mathrm{~g}$ of each material (WB, RS, SB, CC, SD, GS and LL) individually moistened $(70 \%)$ with the liquid media containing (g/L) $\left(\mathrm{NH}_{4}\right)_{2} \mathrm{SO}_{4} 1, \mathrm{CaCl}_{2}$ 0.125, $\mathrm{NaH}_{2} \mathrm{PO}_{4}$ $\mathrm{H}_{2} \mathrm{O} 1$ and $\mathrm{MgSO}_{4} \cdot 7 \mathrm{H}_{2} \mathrm{O} 0.5$ without glucose (Bagewadi et al. 2017). The inoculum was prepared in the form of mycelial pellets by growing Trichoderma harzianum strain HZN10 in the liquid media on a shaking incubator (150 rpm) at $30 \pm 2{ }^{\circ} \mathrm{C}$ for 4 days. SSF was carried out under static conditions for 8-10 days. The enzyme was harvested using sodium phosphate buffer ( $\mathrm{pH}$ 6.0) (Bagewadi et al. 2016b). The supernatant obtained was used as enzyme for determination of laccase activity and for the estimation of proteins. The enzyme was preserved at $4{ }^{\circ} \mathrm{C}$ until further use.

\section{Enzyme assay and analysis of proteins}

The activity of laccase was estimated by the oxidation of 2,2'-azino-bis(3-ethylbenzothiazoline-6-sulfonic acid) (ABTS) $(0.5 \mathrm{mM})$ in accordance with the method reported by Bagewadi et al. (2017). The changes in absorbance $\left(\lambda_{\max }=420 \mathrm{~nm}\right)$ were recorded at 1 -min intervals. One unit of laccase enzyme activity $(U)$ was defined as the amount of laccase that catalysis the oxidation of $1 \mu \mathrm{M}$ of ABTS per minute under defined standard assay conditions. The proteins were assessed by bicinchoninic acid assay (BCA) protein assay kit (Mulla et al. 2016). All the measurements were taken in triplicate, and the results were recorded as mean \pm standard deviation of means.

\section{Screening of factors by Plackett-Burman design (PBD)}

PBD is commonly employed to select significant factors from an array of factors with lesser experimentations ( $\mathrm{Ra}$ jendran et al. 2007). For laccase optimization by Trichoderma harzianum strain HZN10, the independent factors considered for screening by PBD were wheat bran $\left(\mathrm{X}_{1}\right)$, glucose $\left(\mathrm{X}_{2}\right)$, yeast extract $\left(\mathrm{X}_{3}\right)$, ammonium sulfate $\left(\mathrm{X}_{4}\right)$, $\mathrm{Cu}^{2+}$ ions $\left(\mathrm{X}_{5}\right)$ and 2,5-xylidine $\left(\mathrm{X}_{6}\right)$. Other media constituents were kept constant. The six selected factors were experimentally screened with 12 trials in replicates at 2 stages, high $(+1)$ and low $(-1)$. Table 1 represents the actual and coded form of high and low values of factors with whole randomized experimental design. The measured data are the mean of laccase activity (U/g). PBD is based on the first-order polynomial model shown in Eq. (1):

$Y=\beta_{o}+\Sigma \beta_{i} X_{i}$

where $Y$ is the response (laccase production $\mathrm{U} / \mathrm{g}$ ), $\beta_{o}$ is the model intercept, $\beta_{i}$ is the linear coefficient, and $X_{i}$ is the level of the independent factor $(i=1,2,3,4,5$ and 6).

\section{Optimization of process by RSM}

Minitab 17 statistical software was used as a tool for optimization. Central composite design (CCD) under RSM was selected for process optimization of laccase production by Trichoderma harzianum strain HZN10. The significant factors obtained from PBD were further selected for RSM. Five independent factors selected were wheat bran (A), glucose (B), yeast extract (C), $\mathrm{Cu}^{2+}$ ions (D) and $\mathrm{pH}(\mathrm{E})$. The factors were set at five coded levels $(-\alpha,-1,0,+1$ and $+\alpha)$. Coding of the levels of the factor refers to transforming the analyzed real value into coordinates inside a scale without dimension and which is proportional at its location in the experimental space (Bezerra et al. 2008). The studied real value of coded level $-\alpha$ is 
Table 1 PBD matrix for the screening of independent variables with actual and coded values affecting laccase production

\begin{tabular}{|c|c|c|c|c|c|c|c|c|}
\hline \multirow[t]{2}{*}{$\begin{array}{l}\text { Run } \\
\text { No. }\end{array}$} & \multirow{2}{*}{$\begin{array}{l}\mathrm{X}_{1} \\
\text { Wheat bran }(\mathrm{g} / \\
50 \mathrm{ml})\end{array}$} & \multirow{2}{*}{$\begin{array}{l}\mathrm{X}_{2} \\
\text { Glucose } \\
\quad(\%)\end{array}$} & \multirow{2}{*}{$\begin{array}{l}X_{3} \\
\text { Yeast extract } \\
(\%)\end{array}$} & \multirow{2}{*}{$\begin{array}{l}\mathrm{X}_{4} \\
\text { Ammonium sulfate } \\
(\%)\end{array}$} & \multirow{2}{*}{$\begin{array}{l}\mathrm{X}_{5} \\
\mathrm{Cu}^{2+} \text { ions } \\
\quad(\%)\end{array}$} & \multirow{2}{*}{$\begin{array}{l}\mathrm{X}_{6} \\
2,5 \text {-xylidine } \\
\quad(\%)\end{array}$} & \multicolumn{2}{|c|}{$\begin{array}{l}\text { Laccase production } \\
(\mathrm{U} / \mathrm{g})\end{array}$} \\
\hline & & & & & & & Observed & Predicted \\
\hline 1 & $10.0(+1)$ & $1.0(-1)$ & $0.6(+1)$ & $0.15(-1)$ & $0.015(-1)$ & $0.012(-1)$ & 196 & 197 \\
\hline 2 & $10.0(+1)$ & $2.0(+1)$ & $0.3(-1)$ & $0.3(+1)$ & $0.015(-1)$ & $0.012(-1)$ & 215 & 215 \\
\hline 3 & $5.0(-1)$ & $2.0(+1)$ & $0.6(+1)$ & $0.15(-1)$ & $0.03(+1)$ & $0.012(-1)$ & 180 & 178 \\
\hline 4 & $10.0(+1)$ & $1.0(-1)$ & $0.6(+1)$ & $0.3(+1)$ & $0.015(-1)$ & $0.024(+1)$ & 204 & 199 \\
\hline 5 & $10.0(+1)$ & $2.0(+1)$ & $0.3(-1)$ & $0.3(+1)$ & $0.03(+1)$ & $0.012(-1)$ & 228 & 227 \\
\hline 6 & $10.0(+1)$ & $2.0(+1)$ & $0.6(+1)$ & $0.15(-1)$ & $0.03(+1)$ & $0.024(+1)$ & 240 & 244 \\
\hline 7 & $5.0(-1)$ & $2.0(+1)$ & $0.6(+1)$ & $0.3(+1)$ & $0.015(-1)$ & $0.024(+1)$ & 163 & 168 \\
\hline 8 & $5.0(-1)$ & $1.0(-1)$ & $0.6(+1)$ & $0.3(+1)$ & $0.03(+1)$ & $0.012(-1)$ & 150 & 144 \\
\hline 9 & $5.0(-1)$ & $1.0(-1)$ & $0.3(-1)$ & $0.3(+1)$ & $0.03(+1)$ & $0.024(+1)$ & 120 & 124 \\
\hline 10 & $10.0(+1)$ & $1.0(-1)$ & $0.3(-1)$ & $0.15(-1)$ & $0.03(+1)$ & $0.024(+1)$ & 190 & 188 \\
\hline 11 & $5.0(-1)$ & $2.0(+1)$ & $0.3(-1)$ & $0.15(-1)$ & $0.015(-1)$ & $0.024(+1)$ & 154 & 145 \\
\hline 12 & $5.0(-1)$ & $1.0(-1)$ & $0.3(-1)$ & $0.15(-1)$ & $0.015(-1)$ & $0.012(-1)$ & 105 & 110 \\
\hline
\end{tabular}

-2.37841 and $+\alpha$ is +2.37841 . Table 2 represents the range of values of factors in actual and coded form. Other media components were kept unchanged. Table 3 presents the investigational execution strategy of designated factors with 52 trial runs carried out in replicates.

The relationship among the coded arrangements of the input factors and the actual value of wheat bran, glucose, yeast extract, $\mathrm{Cu}^{2+}$ ions and $\mathrm{pH}$ are described in Eq. (2):

$X_{i}=\frac{\left(Z_{i}-Z_{0}\right)}{\Delta Z}$

where $X_{\mathrm{i}}$ is a coded value, $Z_{\mathrm{i}}$ is the actual value of the factor, $Z_{0}$ is the actual value of the identical factor at the midpoint, and $\Delta Z$ is the step change in the factor. The mean response (laccase yield $\mathrm{U} / \mathrm{g}$ ) is the combinational effects of 5 independent factors studied in a defined range. The laccase yield U/g as measured response ( $\mathrm{Y}$ ) was fitted by second-order polynomial Eq. (3).

$$
\begin{aligned}
Y= & \beta_{o}+\beta_{1} A+\beta_{2} B+\beta_{3} C+\beta_{4} D+\beta_{5} E \\
& +\beta_{11} A^{2}+\beta_{22} B^{2}+\beta_{33} C^{2}+\beta_{44} D^{2}+\beta_{55} E^{2} \\
& +\beta_{12} A B+\beta_{13} A C+\beta_{14} A D+\beta_{15} A E+\beta_{23} B C \\
& +\beta_{24} B D+\beta_{25} B E+\beta_{34} C D+\beta_{35} C E,
\end{aligned}
$$

where $Y$ is the measured response (laccase production $\mathrm{U} / \mathrm{g}$ ), $A, B, C, D$ and $E$ are independent factors, $\beta_{1}, \beta_{2}, \beta_{3}, \beta_{4}, \beta_{5}$ are linear coefficients, $\beta_{11}, \beta_{22}, \beta_{33}, \beta_{44}, \beta_{55}$ are quadratic coefficients, and $\beta_{12}, \beta_{13}, \beta_{14}, \beta_{15}, \beta_{23}, \beta_{24}, \beta_{25}, \beta_{34}, \beta_{35}$ are cross product coefficients of the model. Statistical analysis of data and response surface plots of the model was performed using the same software. The statistical significance of the model terms was studied using ANOVA. The significance of the model was assessed using Fisher's ' $F$ ' test and its corresponding probability ' $p$ '. Coefficient of determination $R^{2}$ and adjusted $R^{2}$ predicted the model's accuracy statistically. The model adequacy was experimentally validated in triplicate at optimized levels of factors (Bagewadi et al. 2016a). During the optimization, the laccase activity was determined as mentioned previously.

\section{Application of laccase in delignification of biomass}

Delignification of mild alkali $(\mathrm{NaOH})$-pretreated saw dust (Biomass) was carried out using optimized laccase produced from Trichoderma harzianum strain HZN10. Reaction was performed in 100-ml glass (Erlenmeyer) flasks, comprising $1 \mathrm{~g}$ (dry weight) of pretreated saw dust in $10 \mathrm{ml}$ of $50 \mathrm{mM}$ sodium phosphate buffer ( $\mathrm{pH}$ 6.0) with
Table 2 Actual and coded level of independent variables tested with CCD-RSM design for laccase production

\begin{tabular}{lllllll}
\hline Independent process variable & Symbol code & \multicolumn{7}{l}{ Actual values of coded variables } \\
\cline { 3 - 6 } & & $+\alpha$ & +1 & 0 & -1 & $-\alpha$ \\
\hline Wheat bran $(\mathrm{g} / 50 \mathrm{ml})$ & $\mathrm{A}$ & 31.85 & 25 & 20 & 15 & 8.15 \\
Glucose $(\%)$ & $\mathrm{B}$ & 10.75 & 8.0 & 6.0 & 4.0 & 1.25 \\
Yeast extract (\%) & $\mathrm{C}$ & 1.475 & 1.2 & 1.0 & 0.8 & 0.53 \\
$\mathrm{Cu}^{2+}$ ions $(\%)$ & $\mathrm{D}$ & 0.0625 & 0.0525 & 0.045 & 0.0375 & 0.0275 \\
$\mathrm{pH}$ & $\mathrm{E}$ & 8.15 & 7.5 & 7.0 & 6.5 & 5.85 \\
\hline
\end{tabular}


Table 3 Experimental design matrix for CCD-RSM of significant variables affecting laccase production

\begin{tabular}{|c|c|c|c|c|c|c|c|}
\hline \multirow[t]{2}{*}{ Run no. } & \multirow{2}{*}{$\begin{array}{l}\text { A } \\
\text { Wheat bran }(\mathrm{g} / 50 \mathrm{ml})\end{array}$} & \multirow{2}{*}{$\begin{array}{l}\text { B } \\
\text { Glucose }(\%)\end{array}$} & \multirow{2}{*}{$\begin{array}{l}\mathrm{C} \\
\text { Yeast extract }(\%)\end{array}$} & \multirow{2}{*}{$\begin{array}{l}\mathrm{D} \\
\mathrm{Cu}^{2+} \text { ions }(\%)\end{array}$} & \multirow{2}{*}{$\begin{array}{l}\mathrm{E} \\
\mathrm{pH}\end{array}$} & \multicolumn{2}{|c|}{ Laccase production $(\mathrm{U} / \mathrm{g})$} \\
\hline & & & & & & Observed & Predicted \\
\hline 1 & -1 & -1 & -1 & -1 & -1 & 152 & 113 \\
\hline 2 & +1 & -1 & -1 & -1 & -1 & 393 & 339 \\
\hline 3 & -1 & +1 & -1 & -1 & -1 & 79 & 67 \\
\hline 4 & +1 & +1 & -1 & -1 & -1 & 283 & 267 \\
\hline 5 & -1 & -1 & +1 & -1 & -1 & 130 & 171 \\
\hline 6 & +1 & -1 & +1 & -1 & -1 & 420 & 424 \\
\hline 7 & -1 & +1 & +1 & -1 & -1 & 98 & 146 \\
\hline 8 & +1 & +1 & +1 & -1 & -1 & 422 & 373 \\
\hline 9 & -1 & -1 & -1 & +1 & -1 & 92 & 70 \\
\hline 10 & +1 & -1 & -1 & +1 & -1 & 102 & 160 \\
\hline 11 & -1 & +1 & -1 & +1 & -1 & 73 & 76 \\
\hline 12 & +1 & +1 & -1 & +1 & -1 & 104 & 140 \\
\hline 13 & -1 & -1 & +1 & +1 & -1 & 200 & 182 \\
\hline 14 & +1 & -1 & +1 & +1 & -1 & 352 & 299 \\
\hline 15 & -1 & +1 & +1 & +1 & -1 & 220 & 209 \\
\hline 16 & +1 & +1 & +1 & +1 & -1 & 296 & 300 \\
\hline 17 & -1 & -1 & -1 & -1 & +1 & 70 & 119 \\
\hline 18 & +1 & -1 & -1 & -1 & +1 & 381 & 377 \\
\hline 19 & -1 & +1 & -1 & -1 & +1 & 170 & 166 \\
\hline 20 & +1 & +1 & -1 & -1 & +1 & 370 & 397 \\
\hline 21 & -1 & -1 & +1 & -1 & +1 & 262 & 174 \\
\hline 22 & +1 & -1 & +1 & -1 & +1 & 460 & 460 \\
\hline 23 & -1 & +1 & +1 & -1 & +1 & 255 & 242 \\
\hline 24 & +1 & +1 & +1 & -1 & +1 & 485 & 500 \\
\hline 25 & -1 & -1 & -1 & +1 & +1 & 84 & 49 \\
\hline 26 & +1 & -1 & -1 & +1 & +1 & 183 & 171 \\
\hline 27 & -1 & +1 & -1 & +1 & +1 & 72 & 148 \\
\hline 28 & +1 & +1 & -1 & +1 & +1 & 325 & 244 \\
\hline 29 & -1 & -1 & +1 & +1 & +1 & 70 & 159 \\
\hline 30 & +1 & -1 & +1 & +1 & +1 & 330 & 308 \\
\hline 31 & -1 & +1 & +1 & +1 & +1 & 301 & 278 \\
\hline 32 & +1 & +1 & +1 & +1 & +1 & 332 & 401 \\
\hline 33 & -2.37841 & 0 & 0 & 0 & 0 & 80 & 56 \\
\hline 34 & +2.37841 & 0 & 0 & 0 & 0 & 445 & 471 \\
\hline 35 & 0 & -2.37841 & 0 & 0 & 0 & 115 & 153 \\
\hline 36 & 0 & +2.37841 & 0 & 0 & 0 & 245 & 209 \\
\hline 37 & 0 & 0 & -2.37841 & 0 & 0 & 136 & 142 \\
\hline 38 & 0 & 0 & +2.37841 & 0 & 0 & 402 & 398 \\
\hline 39 & 0 & 0 & 0 & -2.37841 & 0 & 174 & 207 \\
\hline 40 & 0 & 0 & 0 & +2.37841 & 0 & 68 & 37 \\
\hline 41 & 0 & 0 & 0 & 0 & -2.37841 & 91 & 118 \\
\hline 42 & 0 & 0 & 0 & 0 & +2.37841 & 270 & 245 \\
\hline 43 & 0 & 0 & 0 & 0 & 0 & 478 & 476 \\
\hline 44 & 0 & 0 & 0 & 0 & 0 & 476 & 476 \\
\hline 45 & 0 & 0 & 0 & 0 & 0 & 474 & 476 \\
\hline 46 & 0 & 0 & 0 & 0 & 0 & 476 & 476 \\
\hline 47 & 0 & 0 & 0 & 0 & 0 & 475 & 476 \\
\hline
\end{tabular}


Table 3 continued

\begin{tabular}{|c|c|c|c|c|c|c|c|}
\hline \multirow[t]{2}{*}{ Run no. } & \multirow{2}{*}{$\begin{array}{l}\text { A } \\
\text { Wheat bran }(\mathrm{g} / 50 \mathrm{ml})\end{array}$} & \multirow{2}{*}{$\begin{array}{l}\text { B } \\
\text { Glucose }(\%)\end{array}$} & \multirow{2}{*}{$\begin{array}{l}\mathrm{C} \\
\text { Yeast extract }(\%)\end{array}$} & \multirow{2}{*}{$\begin{array}{l}\mathrm{D} \\
\mathrm{Cu}^{2+} \text { ions }(\%)\end{array}$} & \multirow{2}{*}{$\begin{array}{l}\mathrm{E} \\
\mathrm{pH}\end{array}$} & \multicolumn{2}{|c|}{ Laccase production $(\mathrm{U} / \mathrm{g})$} \\
\hline & & & & & & Observed & Predicted \\
\hline 48 & 0 & 0 & 0 & 0 & 0 & 478 & 476 \\
\hline 49 & 0 & 0 & 0 & 0 & 0 & 476 & 476 \\
\hline 50 & 0 & 0 & 0 & 0 & 0 & 474 & 476 \\
\hline 51 & 0 & 0 & 0 & 0 & 0 & 476 & 476 \\
\hline 52 & 0 & 0 & 0 & 0 & 0 & 475 & 476 \\
\hline
\end{tabular}

$162 \mathrm{U} / \mathrm{mg}$ of laccase and $1 \mathrm{mM}$ HBT mediator. Samples were periodically collected and filtered through $0.45-\mu \mathrm{m}$ filter and diluted appropriately with the eluent. The delignification process was assessed on the basis of the production and release of phenolic compounds before and after the laccase treatment. The phenolic compounds present in the samples were identified by HPLC (Dionex DX600 series).

\section{Enzymatic hydrolysis of laccase-treated biomass}

Enzymatic hydrolysis of laccase (delignified)-treated saw dust was studied using cellulase mixture (Bagewadi et al. 2016 b). Concisely, the reaction mixture consists of $2 \%$ saw dust in $50 \mathrm{mM}$ sodium phosphate buffer $\mathrm{pH} 6.0,0.1 \%$ Tween-40 and filter-sterilized enzyme in a volume of $30.0 \mathrm{ml}$. The hydrolysis was carried out at $40{ }^{\circ} \mathrm{C}$ in rotary shaker $(150 \mathrm{rpm})$. Samples were withdrawn periodically for analysis of reducing sugars (Miller 1959).

\section{Analytical methods}

The phenolic compounds after delignification of saw dust by laccase treatment were analyzed using HPLC. HPLC (Dionex DX-600 series) with $150 \times 4.6 \mathrm{~mm} \mathrm{~S}-3$ column was employed. Gradient elution was carried out using $0.1 \%$ phosphoric acid (v/v) and acetonitrile (10:90) as mobile phase, and the flow rate was set at $0.5 \mathrm{ml} / \mathrm{min}$. The column temperature was maintained at $35^{\circ} \mathrm{C}$. A sample volume of $25 \mu \mathrm{L}$ was injected into the system, and the detection was carried out at a wavelength of $255 \mathrm{~nm}$ (Bagewadi et al. 2016a; Lee et al. 2012). The phenolic compounds in the sample were recognized by matching their retention times with those of authentic standard phenolic compounds like 4-hydroxy-3-methoxybenzoic (vanillic) acid and 4-hydroxy-3,5-dimethoxybenzoic (syringic) acid.

FTIR (PerkinElmer, FTIR 1760) was used to explore the functional group variations during the delignification process in untreated and laccase (from Trichoderma harzianum strain HZN10) biologically pretreated saw dust in the presence of HBT mediator in accordance with Bagewadi et al. (2016a). Spectroscopic grade $\mathrm{KBr}$ (potassium bromide) was used for pellet preparation of sample at $10 \mathrm{MPa}$. The sample spectrum was obtained in a scanning range of $500-4000 \mathrm{~cm}^{-1}$ with background scanning and correction.

The alterations in the morphological and physical properties of untreated and Trichoderma harzianum strain HZN10 (producing laccase) delignified saw dust samples were analyzed by SEM (VEGAITESCAN, USA) (Bagewadi et al. 2016b). The samples were mounted on aluminum stubs and sputter-coated with a gold layer. The images were examined at different magnification.

\section{Results and discussion}

\section{Production of laccase under SSF}

The choice of lignocellulosic material within SSF is a key factor for the efficient and economical yield of the lignolytic enzymes. Various lignocellulosic agricultural waste residues (WB, RS, SB, CC, SD, GS and LL) were checked for synthesis (yield) of laccase under SSF. All the lignocellulosic materials showed fungal growth and its utilization for the production of laccase. The results indicate wheat bran as the potential substrate for production of laccase (63 U/g and $9.6 \mathrm{mg} / \mathrm{g}$ protein) by Trichoderma harzianum strain HZN10 in comparison with other substrates with luxurious growth over the substrate on the 10th day of fermentation as shown in Fig. 1.

Wheat bran is recommended as a balanced substrate for microbial growth as it contains higher cellulosic, hemicellulosic, protein as well as lignin content. It is rich in growth factors and vitamins. It is an abundant by-product formed during wheat flour preparation. Rice straw $(55 \mathrm{U} / \mathrm{g}$ ) and sugarcane bagasse $(53 \mathrm{U} / \mathrm{g}$ ) also showed reasonable laccase activities. However, lowest activity was recorded with leaf litter $(33 \mathrm{U} / \mathrm{g})$. The inducers and compounds that affect the laccase synthesis vary with different substrates. Hence, wheat bran was selected as a solid substrate for further studies. The greater yields with wheat bran are consistent in previous reports on SSF using wheat bran as a substrate. Laccase production using wheat bran is evident 


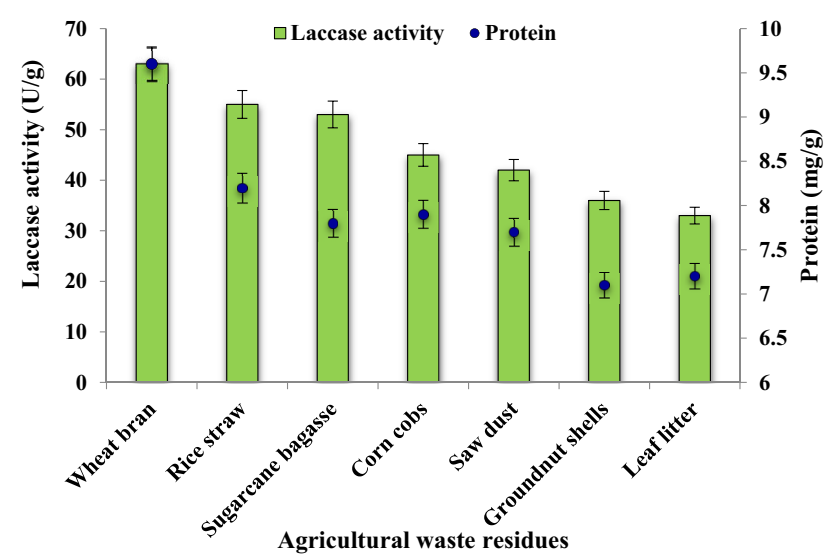

Fig. 1 Production of laccase by Trichoderma harzianum strain HZN10 under SSF using various agricultural waste residues

from previous studies of Cotylidia pannosa (Sharma et al. 2015) and from wheat straw by Trichoderma harzianum ZF-2 (Gao et al. 2013). In agreement with our results, wheat bran also showed the highest laccase activity using Pleurotus ostreatus (El-Batal et al. 2015) and Ganoderma sp. (Revankar et al. 2007). The different types of substrates have a notable effect on the production of laccase. The wheat straw substrate was also observed as most suitable for laccase production by $T$. giganteum AGHP with full colonization of substrate on the 16th day of incubation (Patel and Gupte 2016).

\section{Statistical optimization of laccase production from Trichoderma harzianum strain HZN10}

\section{Screening of significant factors affecting laccase} production by $P B D$

PBD was used to screen the factors for their significant effect on laccase production. Highest laccase production $(240 \mathrm{U} / \mathrm{g})$ was observed in 6th run with a combination of all factors such as wheat bran, glucose, yeast extract, $\mathrm{Cu}^{2+}$ ions and 2,5-xylidine present at high level except for ammonium sulfate which was at low level. Variation in laccase production among the different combinations occurred due to the influence of the factors at high and low levels as shown in Table 1. Wheat bran, glucose, yeast extract and $\mathrm{Cu}^{2+}$ ions had a substantial influence on laccase yield as seen in Table 4. The key effects of the fermentation variables at the consigned levels on laccase yield were described. By the term 'key effects,' the average of achieved results $(\mathrm{U} / \mathrm{g})$, in which respective variable is at given level, is meant. Yield levels were found to be very much reliant on the working conditions. Wheat bran, glucose and yeast extract showed a large effect at high concentrations. Regression study and ANOVA with a $p<0.05$ indicate the significance of the model terms, and $p$ values $>0.1$ indicates the insignificant model terms. A significant positive effect of wheat bran, glucose, yeast extract and $\mathrm{Cu}^{2+}$ ions was verified on laccase yield. The pronounced effect of wheat bran was evidenced to exhibit the highest effect. The coefficient of determination $R^{2}$, adjusted $R^{2}$ and predicted $R^{2}$ were $98.85,97.47$ and $93.36 \%$, respectively, representing high correlation among the observed and predicted values. The regression model describes the correlation existing among the independent variables and the response.

The first-order model was fitted to the experimental results with the following Eq. (4):

$$
\begin{aligned}
Y= & 178.75+33.42 X_{1}+17.92 X_{2}+10.08 X_{3}+1.25 X_{4} \\
& +5.92 X_{5}-0.25 X_{6}
\end{aligned}
$$

where $Y$ is predicted response and $X_{1}, X_{2}, X_{3}, X_{4}, X_{5}$ and $X_{6}$ are the coded values of wheat bran, glucose, yeast extract, ammonium sulfate, $\mathrm{Cu}^{2+}$ ions and 2,5-xylidine, respectively.

\begin{tabular}{|c|c|c|c|c|c|c|c|}
\hline Term & Effect & Coefficient & Degree of freedom & Adjusted sum of squares & Adjusted mean squares & $F$ value & $p$ value \\
\hline Model & & & 6 & $18,911.8$ & 3152.0 & 71.50 & $0.001 *$ \\
\hline Constant & & 178.75 & & & & & $<0.001^{*}$ \\
\hline $\mathrm{X}_{1}$-wheat bran & 66.83 & 33.42 & 1 & $13,400.1$ & $13,400.1$ & 303.97 & $<0.001 *$ \\
\hline $\mathrm{X}_{2}$-glucose & 35.83 & 17.92 & 1 & 3852.1 & 3852.1 & 87.38 & $<0.001^{*}$ \\
\hline $\mathrm{X}_{3}$-yeast extract & 20.17 & 10.08 & 1 & 1220.1 & 1220.1 & 27.68 & $0.003^{*}$ \\
\hline $\mathrm{X}_{4}$-ammonium sulfate & 2.50 & 1.25 & 1 & 18.7 & 18.7 & 0.43 & 0.543 \\
\hline $\mathrm{X}_{5}-\mathrm{Cu}^{2+}$ ions & 11.83 & 5.92 & 1 & 420.1 & 420.1 & 9.53 & $0.027 *$ \\
\hline $\mathrm{X}_{6}-2,5$-xylidine & -0.50 & -0.25 & 1 & 0.8 & 0.8 & 0.02 & 0.901 \\
\hline Residual error & & & 5 & 220.4 & 44.1 & & \\
\hline Total & & & 11 & $19,132.3$ & & & \\
\hline
\end{tabular}

Table 4 Regression coefficient and analysis of variance for the quadratic model for laccase production

$F$ is Fisher's function; probability $*(p<0.05)$ corresponds to significance

$R^{2}=98.85 \%$; adjusted $R^{2}=97.47 \% ; R^{2}$ pred $=93.36 \%$; coefficient of variation $(\mathrm{CV})=6.6$ 


\section{Optimization of laccase production by CCD-RSM design}

Optimization of culture conditions by preliminary screening through PBD showed that wheat bran, glucose, yeast extract and $\mathrm{Cu}^{2+}$ ions are key fermentation variables for laccase yield by Trichoderma harzianum strain HZN10 under SSF. However, the preliminary methods of optimization do not provide any evidence about interactive effects of the variables responsible for higher yield, which are also known to positively regulate the fungal metabolism. Thus, statistical optimization of significant variables for maximizing laccase yield by Trichoderma harzianum strain HZN10 was executed by CCD-RSM design with five factors in 52 experimental trials. These variables and their levels were chosen based on the preliminary experiments. The 52 experimental trials reflected the different combinations of the factors. The tentative (experimental) replies for the 52 trials are presented in Table 3 which shows substantial deviation in laccase yield. The variations were based on 5 independent factors present in the medium. The lowest and highest laccase yield achieved was 68 and 478 $\mathrm{U} / \mathrm{g}$, respectively. The results revealed that the run number 43 gave the highest enzyme activity ( $478 \mathrm{U} / \mathrm{g}$ ) with all of the variables present in their middle (' 0 ') levels which were wheat bran $20 \mathrm{~g} / 50 \mathrm{ml}$, glucose $6 \%$, yeast extract $1 \%$, $\mathrm{Cu}^{2+}$ ions $0.045 \%$ and $\mathrm{pH} 7.0$. Identifying the influence of individual variable is a vital step for an effective fermentation method. ANOVA was used to examine the results of the experiments and to find out how much variations each variable has contributed. As shown in Table 5, from the ' $F$ ' value of all chosen variables, it was observed that all variables and interactions considered in the investigational design were statistically significant at $95 \%$ confidence level, demonstrating that almost all the variability of investigational data can be described in terms of significant effects. Statistical investigation of the laccase yield from

Table 5 Analysis of variance for response surface quadratic model for laccase production

\begin{tabular}{|c|c|c|c|c|c|c|}
\hline Source & Coefficient & Degree of freedom & Sum of squares & Mean squares & $F$ value & $p$ value \\
\hline Model & & 20 & 115,414 & 57,707 & 27.24 & $<0.001 *$ \\
\hline Linear & & 5 & 547,501 & 109,500 & 51.68 & $<0.001 *$ \\
\hline A-wheat bran & 87.23 & 1 & 329,554 & 329,554 & 155.55 & $<0.001 *$ \\
\hline B-glucose & 11.85 & 1 & 6080 & 6080 & 2.87 & 0.100 \\
\hline $\mathrm{C}$-yeast extract & 53.85 & 1 & 125,625 & 125,625 & 59.29 & $<0.001 *$ \\
\hline $\mathrm{D}-\mathrm{Cu}^{2+}$ ions & -35.70 & 1 & 55,190 & 55,190 & 26.05 & $<0.001^{*}$ \\
\hline $\mathrm{E}-\mathrm{pH}$ & 26.78 & 1 & 31,052 & 31,052 & 14.66 & $0.001 *$ \\
\hline Square & & 5 & 534,431 & 106,886 & 50.45 & $<0.001 *$ \\
\hline $\mathrm{A}^{2}$-wheat bran $*$ wheat bran & -37.45 & 1 & 82,071 & 82,071 & 38.74 & $<0.001 *$ \\
\hline $\mathrm{B}^{2}$-glucose $*$ glucose & -52.03 & 1 & 158,446 & 158,446 & 74.78 & $<0.001 *$ \\
\hline $\mathrm{C}^{2}$-yeast extract $*$ yeast extract & -36.30 & 1 & 77,112 & 77,112 & 36.40 & $<0.001 *$ \\
\hline $\mathrm{D}^{2}-\mathrm{Cu}^{2+}$ ions $* \mathrm{Cu}^{2+}$ ions & -62.46 & 1 & 228,335 & 228,335 & 107.77 & $<0.001 *$ \\
\hline $\mathrm{E}^{2}-\mathrm{pH} * \mathrm{pH}$ & -51.94 & 1 & 157,908 & 157,908 & 74.53 & $<0.001^{*}$ \\
\hline 2-way interaction & & 10 & 72,208 & 7221 & 3.41 & $0.004 *$ \\
\hline $\mathrm{AB}$-wheat bran * glucose & -6.62 & 1 & 1404 & 1404 & 0.66 & 0.422 \\
\hline AC-wheat bran $*$ yeast extract & 6.62 & 1 & 1405 & 1405 & 0.66 & 0.422 \\
\hline $\mathrm{AD}$-wheat bran $* \mathrm{Cu}^{2+}$ ions & -33.94 & 1 & 36,856 & 36,856 & 17.40 & $<0.001^{*}$ \\
\hline $\mathrm{AE}$-wheat bran $* \mathrm{pH}$ & 7.94 & 1 & 2016 & 2016 & 0.95 & 0.337 \\
\hline $\mathrm{BC}$-glucose $*$ yeast extract & 5.19 & 1 & 861 & 861 & 0.41 & 0.528 \\
\hline $\mathrm{BD}$-glucose $* \mathrm{Cu}^{2+}$ ions & 13.00 & 1 & 5408 & 5408 & 2.55 & 0.120 \\
\hline $\mathrm{BE}-$ glucose $* \mathrm{pH}$ & 23.00 & 1 & 16,928 & 16,928 & 7.99 & $0.008 *$ \\
\hline $\mathrm{CD}$ —yeast extract $* \mathrm{Cu}^{2+}$ ions & 13.50 & 1 & 5832 & 5832 & 2.75 & 0.107 \\
\hline $\mathrm{CE}$-yeast extract $* \mathrm{pH}$ & -0.63 & 1 & 13 & 13 & 0.01 & 0.939 \\
\hline $\mathrm{DE}-\mathrm{Cu}^{2+}$ ions $* \mathrm{pH}$ & -6.81 & 1 & 1485 & 1485 & 0.70 & 0.409 \\
\hline Residual error & & 31 & 65,680 & 2119 & 1526.2 & $<0.001^{\mathrm{a}}$ \\
\hline Lack of fit & & 22 & 65,662 & 2985 & & \\
\hline Pure error & & 9 & 18 & 2 & & \\
\hline Total & & 51 & 121,982 & & & \\
\hline
\end{tabular}

$R^{2}=94.62 \%$; adjusted $R^{2}=91.14 \%$; coefficient of variation $(\mathrm{CV})=3.8 ; F$ is Fisher's function; probability $p *(p<0.05)$ corresponds to significance; $p^{\text {a }}$ corresponds to insignificance 
the investigational designs showed that between all chosen variables wheat bran contributed enormously to the overall enzyme yield followed by yeast extract. The computed $F$ value (27.24) shows that the model was significant at a maximum confidence level. The low probability $p$ value $(p<0.05)$ of the model reveals the significance of the model terms. The maximum significance of the model was showed by the correlation coefficient $R^{2}=94.62 \%$. Moreover, $R^{2}$ is in reasonable agreement with the adjusted coefficient $R^{2}=91.14 \%$ representing a maximum correlation among the practically noted and predicted values. However, $94.62 \%$ of the consistency could be clarified by the model and $5.38 \%$ of the total variations were not explained by the model. A minor value of the coefficient of difference of 3.8 reveals a maximum level of accuracy in the obtained data. An insignificant value for the lack of fit showed that the quadratic model was valid for the present study. The $p<0.05$ for $\mathrm{A}, \mathrm{C}, \mathrm{D}, \mathrm{E}, \mathrm{A}^{2}, \mathrm{~B}^{2}, \mathrm{C}^{2}, \mathrm{D}^{2}, \mathrm{E}^{2}, \mathrm{AD}$ and $\mathrm{BE}$ revealed the significance of these model terms as shown in Table 5.

The negative quadratic coefficient value of the factors suggests the existence of a peak point for laccase production with respect to the factors and an inhibitory effect at other than the peak point. A positive linear coefficient value for $\mathrm{A}, \mathrm{C}, \mathrm{E}$ indicates increased laccase production with increased concentrations of wheat bran and yeast extract at greater $\mathrm{pH}$. The collective effects of the process factors on the laccase yield could be expressed in the form of Eq. (5): where insignificant process parameters have been excluded from the quadratic polynomial equation of the model.

$$
\begin{aligned}
Y=476 & +87.23 A+53.85 C-35.70 D+26.78 E \\
& -37.45 A^{2}-52.03 B^{2}-36.30 C^{2} \\
& -62.46 D^{2}-51.94 E^{2}-33.94 A D+23.00 B E
\end{aligned}
$$

where $Y$ is the response (laccase production $\mathrm{U} / \mathrm{g}$ ) and $A, B$, $C, D$ and $E$ are the coded values of the independent variables.

Studying the interaction among two variables provides a deeper insight into the whole process analysis. A factor can interrelate with any or all of the other variables making the possibility of existence of a vast number of interactions. Three-dimensional response surface plots were made in order to examine the interaction between the factors and to identify the optimum concentration of individual factor for highest laccase yield by Trichoderma harzianum strain HZN10. Interactions between two variables were analyzed while keeping the other variable at midpoint. Significant interactions $(p<0.05)$ were identified among wheat bran$\mathrm{Cu}^{2+}$ ions and glucose-pH. Value of $p>0.05$ for $A B, A C$, $A E, B C, B D, C D, C E$ and $D E$ showed insignificant interactions. The negative value of coefficients for $D, A^{2}$, $B^{2}, C^{2}, D^{2}, E^{2}, A B, A D, C E$ and $D E$ specifies that the laccase yield was affected at points other than optimal point. Highest laccase yield occurred with wheat bran $(25-31.85 \mathrm{~g} / 50 \mathrm{ml})$ and $\mathrm{Cu}^{2+}$ ions $(0.045 \%)$ concentrations as shown in Fig. 2a. Medium concentration of glucose (4-6 g) and high pH 7.0-7.5 showed higher laccase titers Fig. 2b. Higher concentration of wheat bran supported higher laccase titers as wheat bran provides the required nutrients and also serves as a better source of carbon and nitrogen required for laccase synthesis. $\mathrm{Cu}^{2+}$ ions at a concentration of $0.045 \%$ induced the laccase synthesis. Higher concentration of copper has a negative effect on growth of fungal culture and thus on laccase activity. Neutral $\mathrm{pH}$ was sufficient for high laccase titers. Additional investigations were carried out in triplicate to confirm the optimal predictions of the model. Laccase yield under optimized conditions (wheat bran $31.85 \mathrm{~g} / 50 \mathrm{ml}$, $\mathrm{Cu}^{2+}$ ions $0.045 \%$; glucose $6.0 \%$ and $\mathrm{pH} 7.5$ ) yielded 510 $\mathrm{U} / \mathrm{g}$ as compared to predicted yield of $514 \mathrm{U} / \mathrm{g}$. An 8.09fold increase in laccase yield was achieved after statistical optimization. The investigation results showed high
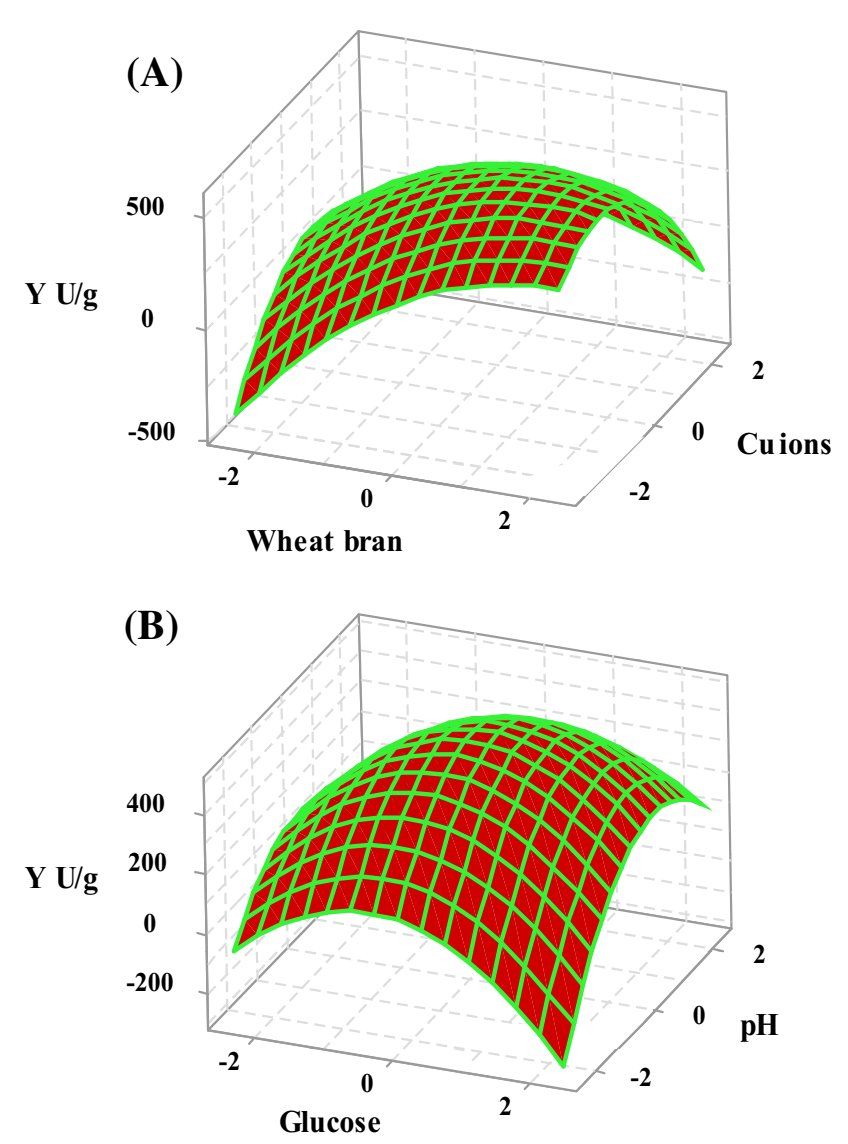

Fig. $23 \mathrm{D}$ response surface plots showing interactions between independent variables. a Wheat bran $v \mathrm{Cu}^{2+}$ ions and $\mathbf{b}$ glucose vs $\mathrm{pH}$ affecting the laccase production (U/g) 
accuracy of model signifying the model validation under the tested conditions.

Among statistical methods, PBD and RSM designs are preferred for optimizing biotechnological processes. The secretion of enzyme depends on the physiological, nutritional and biochemical nature of the organism. Similar to our results, utilization of Taguchi $\mathrm{L}_{18}$ orthogonal array for laccase yield by Coriolopsis caperata RCK2011 revealed that wheat bran had stronger influence on laccase production (Nandal et al. 2013). Generally, wheat bran is used as a lignocellulosic source, which provides both carbon and nitrogen source to the organisms. Supplementation of yeast extract as nitrogen source further improves the fungal growth during early phases of colonization. Copper has been reported to be a strong laccase inducer by many researchers. In Ganoderma sp. rckk-02, laccase yield from was optimized by CCD-RSM with wheat bran substrate and the presence of $\mathrm{Cu}^{2+}$ ions under SSF (Sharma et al. 2015). In agreement with our results, Lorenzo et al. (2005) also found that higher copper concentration $(20 \mathrm{mM})$ inhibited the laccase yield from Trametes versicolor by $40 \%$. Laccase by Ganoderma sp. KU-Alk4 was optimized by a 7-level Box-Behnken factorial design (Teerapatsakul et al. 2007).

\section{Delignification of biomass (Saw dust)}

\section{HPLC analysis of phenolic compounds and enzymatic hydrolysis}

The concentration as well as types of enzyme inhibitors produced in the pretreatment of lignocellulose depends on composition of biomass, pretreatment method and reaction condition (Ximenes et al. 2010). During harsh pretreatment conditions, high phenolic constituent is transformed to the aqueous section. Generally, when biomasses are pretreated, the phenolic substances are derived and released from lignin. The phenolic compounds acted as strong inhibitors of microbial enzymes. Hence, the pretreatment of biomass by laccase aids in the reduction of the phenolic compounds. Filtration and washing of pretreated biomass is known to remove inhibitory compounds, but inhibitors are also released into the media during enzymatic saccharification. Biological pretreatment also improves the digestibility of biomass. Polymeric and monomeric phenolic compounds have been reported to inhibit and deactivate several cellulases from organisms. In the present study, the phenolic compounds present in the laccase-pretreated saw dust hydrolyzate were analyzed after $48 \mathrm{~h}$ using HPLC with authentic standards such as 4-hydroxy-3-methoxybenzoic (vanillic) acid and 4-hydroxy-3,5-dimethoxybenzoic (syringic) acid as shown in Fig. 3a. Peaks at 2.7, 3.2, 3.6 and 4.088 RT are prominently found at higher concentration in
(A)

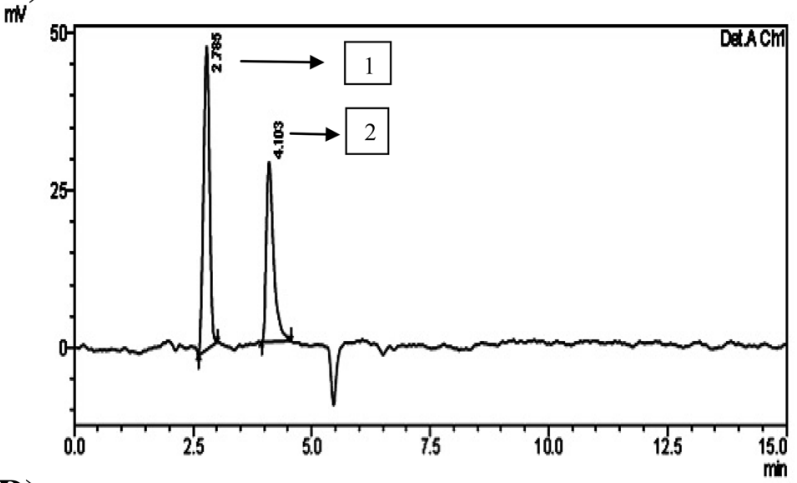

(B)

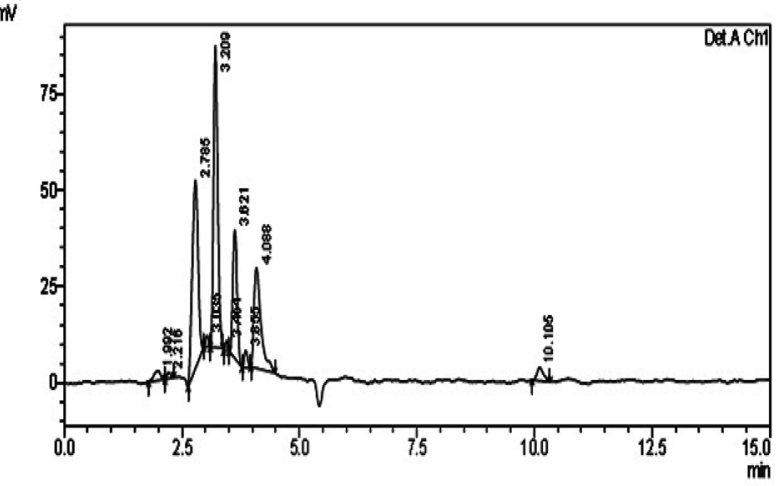

(C)

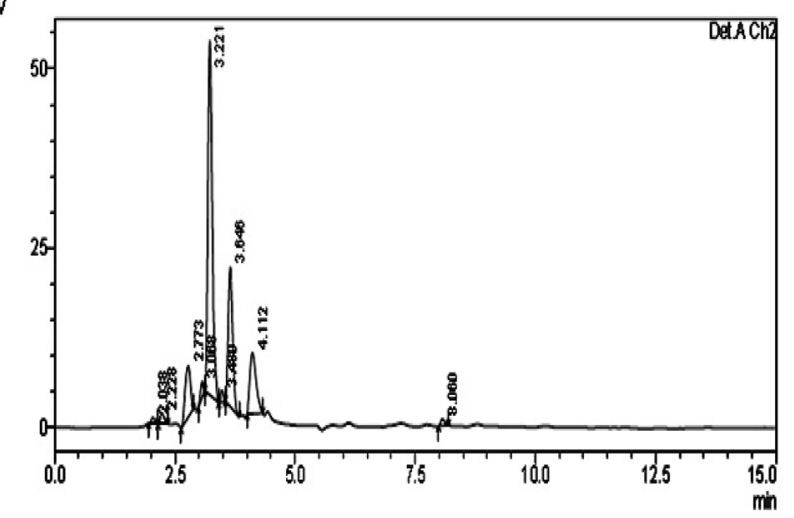

Fig. 3 HPLC chromatogram for a authenticated phenolic compounds. 1: 4-hydroxy-3-methoxybenzoic (vanillic) acid and 2: 4-hydroxy-3,5-dimethoxybenzoic (syringic) acid, b chromatogram of different inhibitors in alkali-pretreated saw dust and c chromatogram of inhibitors during the delignification of biologically pretreated saw dust with laccase from Trichoderma harzianum strain HZN10

untreated saw dust indicating the presence of several inhibitors including vanillic acid and syringic acid Fig. $3 \mathrm{~b}$. Laccase treatment decreased the toxic effects of ligninderived phenolic chemicals like 4-hydroxy-3-methoxybenzoic (vanillic) acid and 4-hydroxy-3,5-dimethoxybenzoic (syringic) acid, which are inhibitory to enzymatic hydrolysis process. Peak at 2.7 RT for 4-hydroxy-3methoxybenzoic (vanillic) acid showed drastic reduction in 
the laccase-pretreated saw dust sample. Peak at $4.1 \mathrm{RT}$ representing 4-hydroxy-3,5-dimethoxybenzoic (syringic) acid also reduced in the laccase-pretreated saw dust sample Fig. 3c.

This resulted in the removal of toxic inhibitors during laccase pretreatment indicating detoxification of the saw dust sample. The untreated saw dust samples were rich in phenolic compounds which drastically reduced upon laccase pretreatment.

The solid fractions of laccase-pretreated and untreated saw dust were subjected for enzymatic saccharification with cellulolytic enzyme mixture. After $72 \mathrm{~h}$ of enzymatic hydrolysis, the hydrolyzates obtained were studied for reducing sugars. The results revealed that the laccase treatment executed prior to the enzymatic hydrolysis of saw dust showed an increase in reducing sugar $(4.3 \mathrm{~g} / \mathrm{g})$ concentration in comparison to untreated sample $(2.7 \mathrm{~g} / \mathrm{g})$. A 1.6-fold increase in reducing sugars was observed after laccase treatment. Hence, laccase pretreatment process seems to be an ecofriendly and advantageous process to achieve enhanced reducing sugars which can be fermented to bioethanol. Previous studies reported that laccase as well as the laccase mediator system can efficiently avoid inhibition by eliminating phenolic compounds and demonstrated the use of laccases for detoxification of biomass. Laccase from Yarrowia lipolytica was used for enzymatic hydrolysis to breakdown phenolic chemicals in pretreated rice straw, which removed $30-52 \%$ of the phenolic compounds with high saccharification yield (Lee et al. 2012). Earlier study demonstrated the use of laccase to strongly reduce the phenolic constituent in the medium, without disturbing weak acids and furan derivatives during the fermentation of steam-exploded wheat straw substrate by Saccharomyces cerevisiae. Whole fermentation lacking accumulation of glucose was found inside $72 \mathrm{~h}$ of simultaneous saccharification and fermentation (Alvira et al. 2013). Use of ligninolytic fungi like Pleurotus eryngii and Irpex lacteus for biological pretreatment of wheat straw biomass was demonstrated indicating maximization of sugar yield and ethanol production and no furfural, 5-hydroxymethylfurfural or acetic or formic acids, the main inhibitors were detected in filtered supernatants after biological treatment (Lopez-Abelairas et al. 2013). Pretreatment of Lantana camara with laccase from Pleurotus sp followed by simultaneous saccharification and fermentation by Saccharomyces cerevisiae yielded $5.14 \%$ (v/v) ethanol (Kuila and Banerjee 2014). A 76\% removal of phenolic compound was observed by laccase (produced from $C$. perennis) treatment of rice straw, and enzymatic hydrolysis of laccase-treated rice straw increased the saccharification yield by $48 \%$ (Kalyani et al. 2012). A reduction in the toxic effect of phenolic compounds by laccase treatment and improved fermentability of hydrolyzates in terms of increased reducing sugar production was demonstrated. Addition of inducers during laccase pretreatment was reported, where $50 \%$ lignin elimination from eucalyptus wood was achieved by pretreatment with recombinant Myceliophthora thermophila laccase and methyl syringate as facilitator (Rico et al. 2014).

\section{FTIR analysis}

The structural alterations in untreated and laccase (from Trichoderma harzianum strain HZN10) biologically pretreated saw dust in the presence of HBT mediator were examined by FTIR. The spectrum of untreated and biologically pretreated saw dust is shown in Fig. 4a, b, respectively.

Broadening of hydroxyl group increased after laccase pretreatment of saw dust. The degradation of lignin was detected after laccase treatment. A peak of amines $\mathrm{N}-\mathrm{H}$ stretch is recognized nearby $3419 \mathrm{~cm}^{-1}$ in both untreated and laccase-pretreated saw dust. Methylene anti-symmetric $\mathrm{C}-\mathrm{H}$ stretch was found around $2928 \mathrm{~cm}^{-1}$. Peak around $2915 \mathrm{~cm}^{-1}$ region in both the cases appears from $\mathrm{C}-\mathrm{H}$ stretching, further suggesting that the treatment process may destroy aliphatic structures in the biomass. A new peak around $1780-1700 \mathrm{~cm}^{-1}$ was detected after laccase treatment indicating the presence of functional groups like aldehyde, ketone, ester and carboxylic acid probably resulting from the laccase action on aromatic ring structure of lignin. In untreated samples, these carbonyl groups stay linked through aromatic rings, thus resulting in no absorption at this wavelength. Strong aromatic ring (aromatic lignin) stretch was experiential in $1600-1500 \mathrm{~cm}^{-1}$ range with aromatic $\mathrm{C}=\mathrm{C}$ bending in untreated saw dust. Lower band intensity at $1605.21 \mathrm{~cm}^{-1}$ in laccase-pretreated sample was observed due to aromatic skeletal vibration. Strong aromatic lignin structure is obvious in untreated sample which was disappearing in laccase pretreatment sample implying delignification effect. Peak around $1550-1500 \mathrm{~cm}^{-1}$ indicated semicircle ring stretching (aromatic lignin) in untreated sample which was lost in laccase-pretreated sample. Peaks near $1500-1450 \mathrm{~cm}^{-1}$ accounted for $-\mathrm{C}-\mathrm{H}$ deformation (methyl and methylene) in untreated sample which disappeared during laccase treatment. A weak $\mathrm{C}-\mathrm{O}$ stretching was found around $1450-1400 \mathrm{~cm}^{-1}$ in untreated sample and lost in treated sample. Peak in the vicinity of $1375 \mathrm{~cm}^{-1}$ corresponded to $\mathrm{O}-\mathrm{H}$ bending of phenols, which is commonly evidenced in raw biomasses. Phenolic clusters are typically considered to be associated with the lignin component of biomass. The more number of phenolic groups indicates the higher lignin content in biomass. Low intensity of this band indicates the destruction of phenolic 

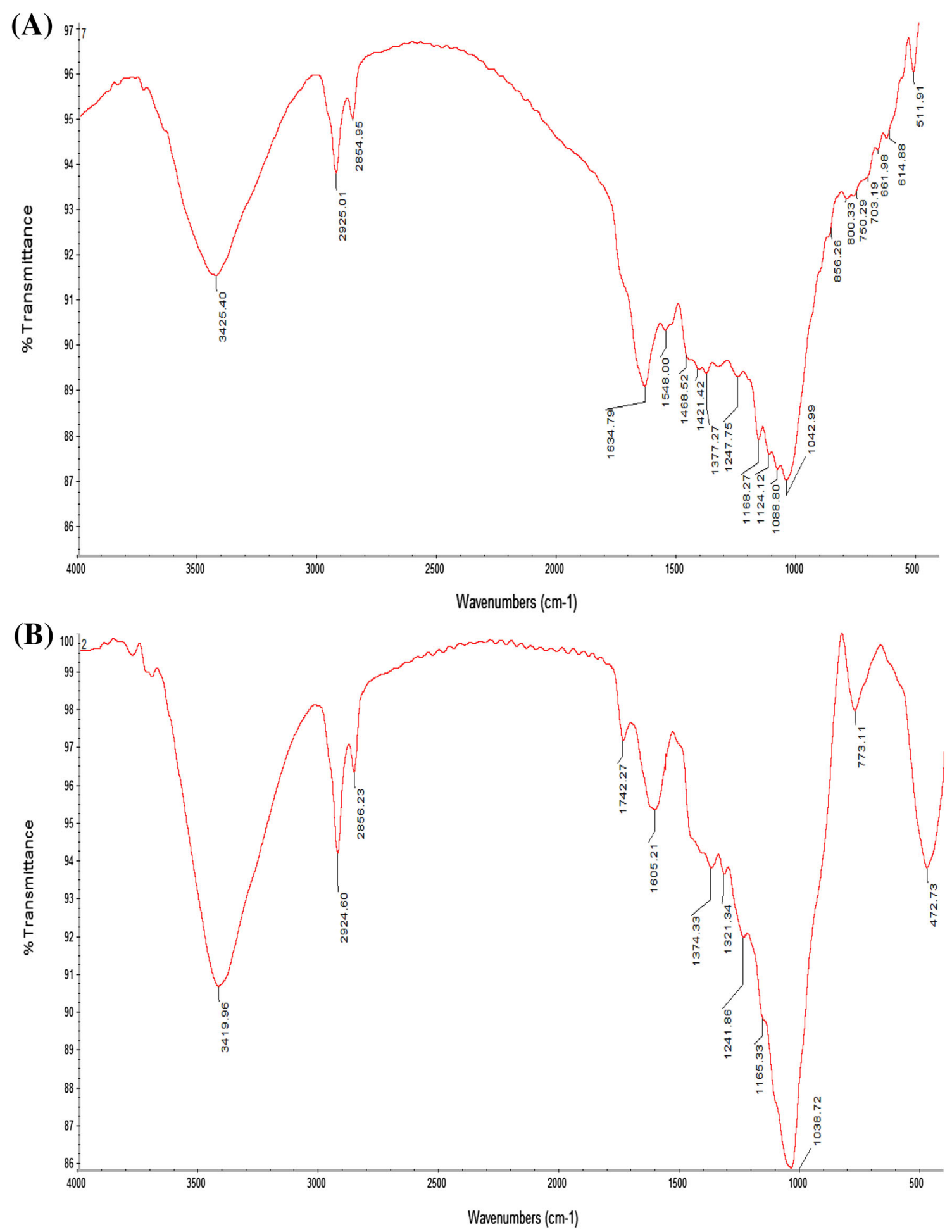

Fig. 4 FTIR analysis of a untreated saw dust and b laccase (from Trichoderma harzianum strain HZN10)-treated saw dust

structures of lignin during laccase action. $\mathrm{C}-\mathrm{O}$ stretching of aryl ethers, and phenolics of lignin-derived chemicals and $\mathrm{C}-\mathrm{O}$ stretching of pyranone rings and guaiacyl monomers around $1250 \mathrm{~cm}^{-1}$ were observed in both samples with varying intensities. Glycosidic linkage was predicted in both samples around $1200-1150 \mathrm{~cm}^{-1}$. Bands around
$1100-950 \mathrm{~cm}^{-1}$ regions revealed the presence of phosphines and phosphine oxides, silican oxide and $\mathrm{C}-\mathrm{O}-\mathrm{C}$ stretching and $\mathrm{C}-\mathrm{O}, \mathrm{C}=\mathrm{C}$ and $\mathrm{C}-\mathrm{C}-\mathrm{O}$ vibrational stretching in the region of $1050-1000 \mathrm{~cm}^{-1}$ which was visualized in both samples. Peaks in the region of $800-856 \mathrm{~cm}^{-1}$ were lost after laccase pretreatment. In untreated saw dust, the 
appearance of peaks near 836 and $1166 \mathrm{~cm}^{-1}$ typically represents the syringyl—guaiacyl-p-hydroxyphenyl (SGH) lignin. Syringyl (S) and guaiacyl (G) units were identified by vibrations of aromatic skeleton around regions of 1609 , 1126 and $1330 \mathrm{~cm}^{-1}$ (S), 1513, 1034 and $1265 \mathrm{~cm}^{-1}$ (G) (Zeng et al. 2011). The decrease in the transmission of these regions revealed the destruction of lignin structures in treated saw dust compared to the untreated. Peak near $780 \mathrm{~cm}^{-1}$ corresponded to aromatic $\mathrm{C}-\mathrm{H}$ bending in both. A peak near $670 \mathrm{~cm}^{-1}$ is usually evidenced in raw biomass for alkyne $\mathrm{C}-\mathrm{H}$ bend which was lost in laccase-treated sample. Peak at $511.91 \mathrm{~cm}^{-1}$ was lost, and new peak at $472.73 \mathrm{~cm}^{-1}$ was evidenced. Earlier reports on FTIR analysis of lignocellulosic biomass also conclude similar observations (Adapa et al. 2011; Qian et al. 2013). FTIR spectra illustrated the delignification process initiated by biological pretreatment of biomass by laccase produced from Trichoderma harzianum strain HZN10. Lignin being a highly branched polymer with an array of functional groups provides many sites for chemical and biological interactions. The significant functional groups in lignin are hydroxyl, methoxy, carbonyl and carboxylic groups. By knowing the mechanism of lignin degradation could help to develop an ecofriendly process of pretreatment to protect the microbial enzymes from the effect of inhibitors during saccharification of biomass. Earlier reports on biological pretreatment of biomass employing laccase also concluded similar observations. Aspergillus fumigatus laccase treatment was done in the presence of a mediator $N$-hydroxybenzotriazole which results in a notable high level of delignification of the pulp. The author reported the appearance of new strong peak at $1720 \mathrm{~cm}^{-1}$ in enzyme-treated pulp (Vivekanand et al. 2008). The delignification efficiency by laccase from $P e$ niophora sp. in the presence of redox mediators (ABTS and HBT) showed structural variations in lignin and occurrence of several active centers for both chemical and biological degradation of lignin following enzymatic treatment. Other authors also showed similar disappearance of peaks after laccase treatment found in untreated pulp at $615 \mathrm{~cm}^{-1}$ (Shankar and Shikha 2012). In agreement with our findings, the spectrum for lignin showed peak at $836 \mathrm{~cm}^{-1}$ for $\mathrm{SGH}$ lignin (Pandiyan et al. 2014).

\section{SEM analysis}

SEM studies depict the morphological and structural variations of biomass arising throughout delignification process. Untreated saw dust revealed a unique structure of the fibers, and the entire structure was closed indicating the recalcitrant nature. It showed intact cell wall with vascular bundles and a highly fibrillar structure as shown in Fig. 5a. SEM image of biologically treated saw dust sample through laccase production by Trichoderma harzianum
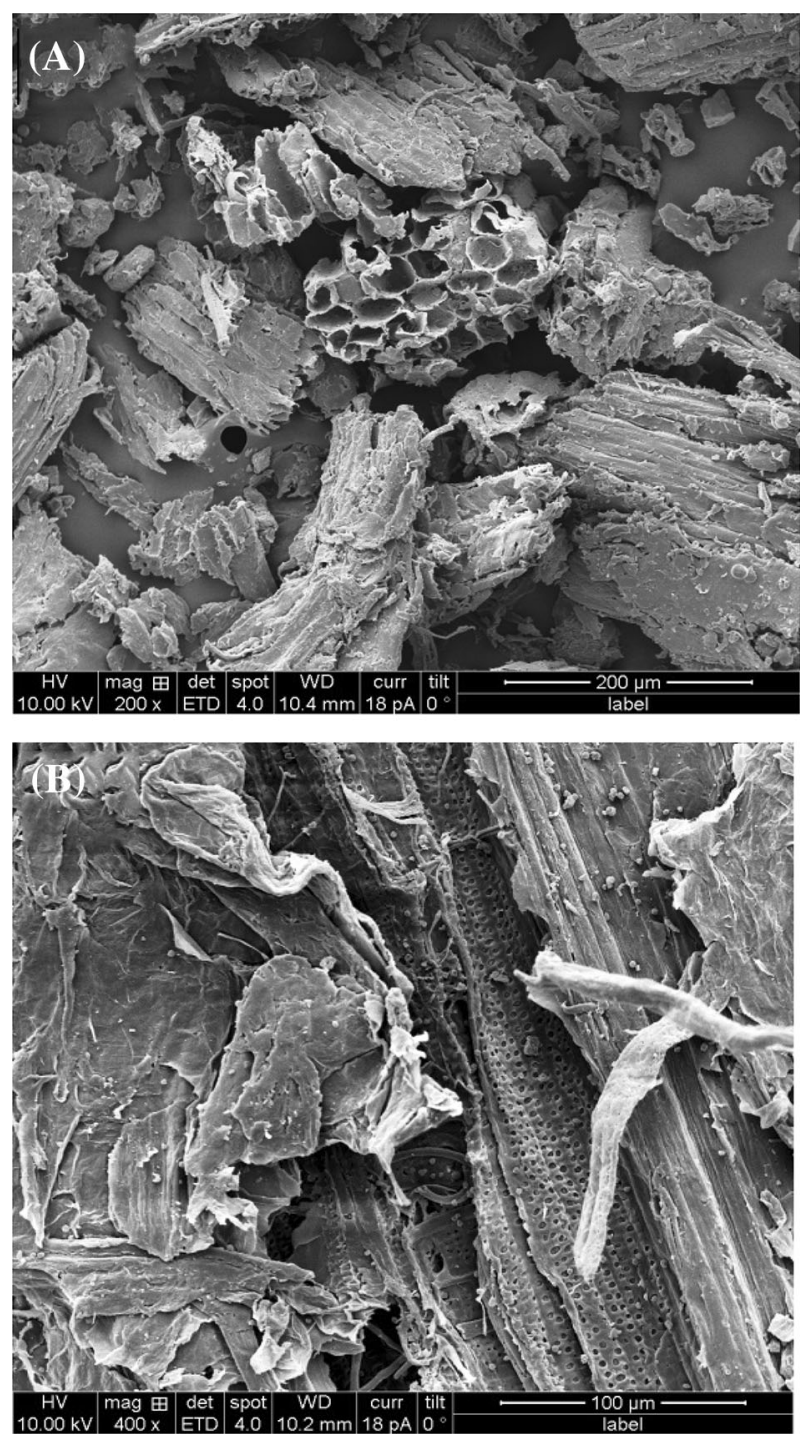

Fig. 5 SEM analysis of a untreated saw dust and b saw dust hydrolyzed by Trichoderma harzianum strain HZN10 producing laccase

strain HZN10 provides important information on the extent and pattern of delignification process targeting the fiber cell walls that are highly rich in lignin. The results validate the interaction between the laccase producer and lignin components of treated sample. The SEM image of the treated sample depicts the colonization of fungi over the wood tissues. The fungal hyphae penetrate into the cells and attack the parenchyma tissue as it supports the fungal growth with available nutrients. Further, the presence of phenolic constituents would have triggered the expression of ligninolytic enzymes by the fungi. This initiates the delignification of biomass which is evidenced at the fiber cells and middle lamella regions (Fig. 5b). The fibers of the laccase-treated sample were shown to possess rough surface. The treated sample reveals the formation of pores on the biomass surface and distraction of the biomass 
matrices. The enhanced porosity further exposes the cellulosic portion for efficient hydrolysis. Similar observations have been reported by other researchers. SEM images of A. mangium wood chip samples biologically treated with T. versicolor, $P$. coccineus, Daedalea sp. as well as Phellinus sp. revealed the mechanism of lignin degradation and its association among ligninolytic enzymes activities formed by fungal cultures (Liew et al. 2011). The enzymatic treatment of wood pulp with Aspergillus fumigates laccase mediator system showed rougher surface indicating the process of peeling with more exterior fibrillation (Vivekanand et al. 2008). Similar structural and chemical variations were observed in Parthenium sp. during chemical and biological pretreatment (Pandiyan et al. 2014).

\section{Conclusions}

In the present research, wheat bran was found to be a potential substrate among the various agricultural waste residues screened for laccase production by Trichoderma harzianum strain HZN10 under SSF. Statistical optimization by PBD and CCD-RSM revealed high model adequacy with 8.09-fold increase in laccase production. Significant interactions were evidenced between wheat bran- $\mathrm{Cu}^{2+}$ ions and glucose-pH. Delignification of saw dust was effective by laccase mediator system. Delignification process was evidenced by HPLC, FTIR and SEM analysis. This indicated the significance of laccase in biofuel industries for biological pretreatment processes.

Acknowledgements First author is grateful to KLE Technological University, Hubballi, for providing all the research facilities.

Author contributions ZB, SM and $\mathrm{HN}$ were involved in experimental design. $\mathrm{ZB}$ and $\mathrm{SM}$ have executed the experimental works. $\mathrm{ZB}, \mathrm{SM}$ and $\mathrm{HN}$ analyzed the results and wrote the manuscript. All authors agreed with the contents of the manuscript.

\section{Compliance with ethical standards}

Conflict of interest The authors declare that they have no conflict of interests.

Open Access This article is distributed under the terms of the Creative Commons Attribution 4.0 International License (http://crea tivecommons.org/licenses/by/4.0/), which permits unrestricted use, distribution, and reproduction in any medium, provided you give appropriate credit to the original author(s) and the source, provide a link to the Creative Commons license, and indicate if changes were made.

\section{References}

Adapa PK, Tabil LG, Schoenau GJ, Canam T, Dumonceaux T (2011) Quantitative analysis of lignocellulosic components of non- treated and steam exploded barley, canola, oat and wheat straw using fourier transform infrared spectroscopy. J Agr Sci Tech B $1: 177-188$

Alvira P, Tomas-Pejo E, Ballesteros M, Negro MJ (2010) Pretreatment technologies for an efficient bioethanol production process based on enzymatic hydrolysis: a review. Bioresour Technol 101(13): 4851-4861. https://doi.org/10.1016/j.biortech.2009.11.093

Alvira P, Moreno AD, Ibarra D, Saez F, Ballesteros M (2013) Improving the fermentation performance of Saccharomyces cerevisiae by laccase during ethanol production from steamexploded wheat straw at high-substrate loadings. Biotechnol Prog 29(1):74-82. https://doi.org/10.1002/btpr.1666

Arora DS, Sharma RK (2010) Ligninolytic fungal laccases and their biotechnological applications. Appl Biochem Biotechnol 160:1760-1788. https://doi.org/10.1007/s12010-009-8676-y

Bagewadi ZK, Mulla SI, Shouche Y, Ninnekar HZ (2016a) Xylanase production from Penicillium citrinum isolate HZN13 using response surface methodology and characterization of immobilized xylanase on glutaraldehyde-activated calcium-alginate beads. 3 . Biotech 6:164. https://doi.org/10.1007/s13205-016-0484-9

Bagewadi Z, Mulla S, Ninnekar H (2016b) Purification and characterization of endo $\beta$-1,4-D-glucanase from Trichoderma harzianum strain HZN11 and its application in production of bioethanol from sweet sorghum bagasse. 3. Biotech 6:101. https://doi.org/10.1007/s13205-016-0421-y

Bagewadi ZK, Mulla SI, Ninnekar HZ (2017) Purification and immobilization of laccase from Trichoderma harzianum strain HZN10 and its application in dye decolorization. J Genet Eng Biotechnol 15:139-150. https://doi.org/10.1016/j.jgeb.2017.01. 007

Bas D, Boyaci IH (2007) Modeling and optimization I: usability of response surface methodology. J Food Eng 78:836-845. https:// doi.org/10.1016/j.jfoodeng.2005.11.024

Bezerra MA, Santelli RE, Oliveira EP, Villar LS, Escaleira LA (2008) Response surface methodology (RSM) as a tool for optimization in analytical chemistry. Talanta 76:965-977. https://doi.org/10. 1016/j.talanta.2008.05.019

Carter B, Squillace P, Gilcrease PC, Menkhaus TJ (2011) Detoxification of a lignocellulosic biomass slurry by soluble polyelectrolyte adsorption for improved fermentation efficiency. Biotechnol Bioeng 108(9):2053-2060. https://doi.org/10.1002/ bit. 23152

Diwaniyan S, Sharma KK, Kuhad RC (2012) Laccase from an Alkalitolerant Basidiomycetes Crinipellis sp. RCK-1: production optimization by response surface methodology. J Basic Microbiol 52(4):397-407. https://doi.org/10.1002/jobm.201100018

El-Batal AI, ElKenawy NM, Yassin AS, Ami n MA (2015) Laccase production by Pleurotus ostreatus and its application in synthesis of gold nanoparticles. Biotechnol Rep 5:31-39. https://doi.org/ 10.1016/j.btre.2014.11.001

Frasconi M, Favero G, Boer H, Koivula A, Mazzei F (2010) Kinetic and biochemical properties of high and low redox potential laccases from fungal and plant origin. Biochim Biophys Acta 1804(4):899-908. https://doi.org/10.1016/j.bbapap.2009.12.018

Gao H, Chu X, Wang Y, Zhou F, Zhao K, Mu Z, Liu Q (2013) Media optimization for laccase production by Trichoderma harzianum ZF-2 using response surface methodology. J Microbiol Biotechnol 23:1757-1764. https://doi.org/10.4014/jmb.1302.02057

Gassara F, Brar SK, Tyagi RD, John RP, Verma M, Valero JR (2011) Parameter optimization for production of ligninolytic enzymes using agro-industrial wastes by response surface method. Biotechnol Bioprocess Eng 16:343-351. https://doi.org/10. 1007/s12257-010-0264-Z

Giardina P, Faraco V, Pezzella C, Piscitelli A, Vanhulle S, Sannia G (2010) Laccases: a never-ending story. Cell Mol Life Sci: CMLS 67(3):369-385. https://doi.org/10.1007/s00018-009-0169-1 
Kalyani D, Dhiman SS, Kim H, Jeya M, Kim IW, Lee JK (2012) Characterization of a novel laccase from the isolated Coltricia perennis and its application to detoxification of biomass. Process Biochem 47:671-678. https://doi.org/10.1016/j.procbio.2012.01.013

Karp SG, Faraco V, Amore A, Letti LAJ, Soccol VT, Soccol CR (2015) Statistical optimization of laccase production and delignification of sugarcane bagasse by Pleurotus ostreatus in solidstate fermentation. Biomed Res Int 2015:8. https://doi.org/10. $1155 / 2015 / 181204$

Kuila A, Banerjee R (2014) Simultaneous saccharification and fermentation of enzyme pretreated Lantana camara using $S$. cerevisiae. Bioprocess Biosyst Eng 37:1963-1969. https://doi. org/10.1007/s00449-014-1172-y

Kumar V, Naik C, Sridhar M (2015) Production, purification and characterization of novel laccase produced by Schizophyllum commune NI-07 with potential for delignification of crop residues. Appl Biochem Microbiol 51(4):432-441. https://doi. org/10.1134/S0003683815040080

Lee KM, Kalyani D, Tiwari MK, Kim TS, Dhiman SS, Lee JK, Kim IW (2012) Enhanced enzymatic hydrolysis of rice straw by removal of phenolic compounds using a novel laccase from yeast Yarrowia lipolytica. Bioresour Technol 123:636-645. https://doi. org/10.1016/j.biortech.2012.07.066

Liew CY, Husaini A, Hussain H, Muid S, Liew KC, Roslan HA (2011) Lignin biodegradation and ligninolytic enzyme studies during biopulping of Acacia mangium wood chips by tropical white rot fungi. World J Microbiol Biotechnol 27(6):1457-1468. https://doi.org/10.1007/s11274-010-0598-x

Lopez-Abelairas M, Alvarez Pallin M, Salvachua D, Lu-Chau T, Martinez MJ, Lema JM (2013) Optimisation of the biological pretreatment of wheat straw with white-rot fungi for ethanol production. Bioprocess Biosyst Eng 36(9):1251-1260. https:// doi.org/10.1007/s00449-012-0869-z

Lorenzo M, Moldes D, Rodriguez Couto S, Sanroman MA (2005) Inhibition of laccase activity from Trametes versicolor by heavy metals and organic compounds. Chemosphere 60(8):1124-1128. https://doi.org/10.1016/j.chemosphere.2004.12.051

Miller GL (1959) Use of dinitrosalicyclic acid reagent for determination of reducing sugar. Biotechnol Bioeng Symp 5:193-219. https://doi.org/10.1021/ac60147a030

Mulla SI, Wang H, Sun Q, Hu A, Yu C-P (2016) Characterization of triclosan metabolism in Sphingomonas sp strain YL-JM2C. Sci Rep 6:21965. https://doi.org/10.1038/srep21965

Myers RH, Montgomery DC (2002) Response surface methodology: product and process optimization using designed experiments, 2nd edn. Wiley, New York. ISBN 978-1-118-91601-8

Nandal P, Ravella SR, Kuhad RC (2013) Laccase production by Coriolopsis caperata RCK2011: optimization under solid state fermentation by Taguchi DOE methodology. Sci Rep 3:1386. https://doi.org/10.1038/srep01386

Pandiyan K, Tiwari R, Rana S, Arora A, Singh S, Saxena AK, Nain L (2014) Comparative efficiency of different pretreatment methods on enzymatic digestibility of Parthenium sp. World J Microbiol Biotechnol 30(1):55-64. https://doi.org/10.1007/s11274-0131422-1

Parawira W, Tekere M (2011) Biotechnological strategies to overcome inhibitors in lignocellulose hydrolysates for ethanol production: review. Crit Rev Biotechnol 31(1):20-31. https:// doi.org/10.3109/07388551003757816

Patel H, Gupte A (2016) Optimization of different culture conditions for enhanced laccase production and its purification from Tricholoma giganteum AGHP. Bioresour Bioprocess 3:11. https://doi.org/10.1186/s40643-016-0088-6

Qian K, Kumar A, Patil K, Bellmer D, Wang D, Yuan W, Huhnke RL (2013) Effects of biomass feedstocks and gasification conditions on the physiochemical properties of char. Energies 6:3972-3986
Rajendran A, Thirugnanam M, Thangavelu V (2007) Statistical evaluation of medium components by Plackett-Burman experimental design and kinetic modeling of lipase production by Pseudomonas fluorescens. Indian J Biotechnol 6:469-478

Revankar MS, Desai KM, Lele SS (2007) Solid-state fermentation for enhanced production of laccase using indigenously isolated Ganoderma sp. Appl Biochem Biotechnol 143:16-26. https:// doi.org/10.1007/s12010-007-0029-0

Rico A, Rencoret J, Del Rio JC, Martinez AT, Gutierrez A (2014) Pretreatment with laccase and a phenolic mediator degrades lignin and enhances saccharification of Eucalyptus feedstock. Biotechnol Biofuels 7(1):6. https://doi.org/10.1186/1754-68347-6

Shankar SS (2012) Laccase production and enzymatic modification of lignin by a novel Peniophora sp. Appl Biochem Biotechnol 166(4):1082-1094. https://doi.org/10.1007/s12010-011-9496-4

Sharma D, Goel G, Sud A, Chauhan RS (2015) A novel laccase from newly isolated Cotylidia pannosa and its application in decolorization of synthetic dyes. Biocatal Agric Biotechnol 4:661-666. https://doi.org/10.1016/j.bcab.2015.07.008

Sun Y, Cheng J (2002) Hydrolysis of lignocellulosic materials for ethanol production: a review. Bioresour Technol 83(1):1-11. https://doi.org/10.1016/S0960-8524(01)00212-7

Taha M, Shahsavari E, Al-Hothaly K, Mouradov A, Smith A, Ball A, Adetutu EM (2015) Enhanced biological straw saccharification through coculturing of lignocellulose-degrading microorganisms. Appl Biochem Biotechnol 175:3709-3728. https://doi.org/ 10.1007/s12010-015-1539-9

Teerapatsakul C, Parra R, Bucke C, Chitradon L (2007) Improvement of laccase production from Ganoderma sp. KU-Alk4 by medium engineering. World J Microbiol Biotechnol 23:1519-1527. https://doi.org/10.1007/s11274-007-9396-5

Viniegra-González G, Favela-Torres N, Aguilar C, Romero-Gómez SJ, Díaz-Godínez G, Augur C (2003) Advantages of fungal enzyme production in solid state over liquid fermentation systems. Biochem Eng J 13:157-167. https://doi.org/10.1016/ S1369-703X(02)00128-6

Vivekanand V, Dwivedi P, Sharma A, Sabharwal N, Singh RP (2008) Enhanced delignification of mixed wood pulp by Aspergillus fumigatus laccase mediator system. World J Microbiol Biotechnol 24:2799-2804. https://doi.org/10.1007/s11274-008-9809-0

Vivekanand V, Dwivedi P, Pareek N, Singh R (2011) Banana peel: a potential substrate for laccase production by Aspergillus fumigates $\mathrm{VkJ} 2.4 .5$ in solid-state fermentation. Appl Biochem Biotechnol 165:204-220. https://doi.org/10.1007/s12010-0119244-9

Wyman CE, Dale BE, Elander RT, Holtzapple M, Ladisch MR, Lee YY (2005) Coordinated development of leading biomass pretreatment technologies. Bioresour Technol 96(18):1959-1966. https://doi.org/10.1016/j.biortech.2005.01. 010

Ximenes E, Kim Y, Mosier N, Dien B, Ladisch M (2010) Inhibition of cellulases by phenols. Enzyme Microb Technol 46:170-176. https://doi.org/10.1016/j.enzmictec.2009.11.001

Zeng J, Singh D, Chen S (2011) Biological pretreatment of wheat straw by Phanerochaete chrysosporium supplemented with inorganic salts. Bioresour Technol 102(3):3206-3214. https:// doi.org/10.1016/j.biortech.2010.11.008

\section{Publisher's Note}

Springer Nature remains neutral with regard to jurisdictional claims in published maps and institutional affiliations 